\title{
Educação ambiental: práticas exitosas a partir de metodologias ativas, na EEEFM “José Teixeira Fialho"
}

A presente pesquisa busca analisar a importância dos projetos de ensino apresentados na sala de aula, e sua aplicabilidade no contexto socioambiental dos estudantes de acordo com a realidade local. Traz uma reflexão acerca dos problemas que o ambiente no entorno da escola, bem como do Distrito sofreram durante anos de ações humanas que levaram a degradação e impactos ambientais. A Escola que a pesquisa aconteceu, está localizada no Distrito de Imburana, Ecoporanga, ES. Os estudantes são provenientes do Distrito, das adjacências, Assentamentos, Acampamentos, dos distritos vizinhos: Cotaxé e Muritiba. As famílias na maioria são de classes econômicas de baixa renda, trabalhando no campo, nas pedreiras, nas fazendas. $O$ estudo da educação ambiental não pode ser algo engessado como tem sido, mas de uma forma prática e objetiva. A presente pesquisa busca responder qual é a importância das práticas exitosas a partir de metodologias ativas, visando uma educação ambiental prática, dialógica e participativa.

Palavras-chave: Educação; Ciência; Tecnologia; Sociedade; Ambiente.

\section{Environmental education: successful practices from active methodologies, at EEEFM "José Teixeira Fialho"}

This research seeks to analyze the importance of teaching projects presented in the classroom, and their applicability in the socio-environmental context of students according to the local reality. It brings a reflection on the problems that the environment around the school, as well as the District, suffered during years of human actions that led to degradation and environmental impacts. The School where the research took place is located in the District of Imburana, Ecoporanga, ES. Students come from the District, neighboring areas, Settlements, Camps, from neighboring districts: Cotaxe and Muritiba. Most families are from low-income economic classes, working in the fields, in quarries, on farms. The study of environmental education cannot be fixed as it has been, but in a practical and objective way. This research seeks to answer the importance of successful practices from active methodologies, aiming at practical, dialogic and participatory environmental education.

Keywords: Education; Science; Technology; Society; Environment.

Topic: Práticas, Didática e Metodologias do Ensino

Reviewed anonymously in the process of blind peer
Received: 22/01/2021

Approved: 19/05/2021
Jailson Mauricio Pinto

Universidade Federal do Espírito Santo, Brasil

http://lattes.cnpq.br/5630364581431753

http://orcid.org/0000-0002-4051-0051

jailsonecop@hotmail.com
Referencing this:

PINTO, J. M.. Educação ambiental: práticas exitosas a partir de metodologias ativas, na EEEFM “José Teixeira Fialho". Humanum Sciences, v.3, n.1, p.23-31, 2021. DOI:

http://doi.org/10.6008/CBPC2674-6654.2021.001.0003 


\section{INTRODUÇÃO}

A escola, o currículo e toda a organização escolar, devem estar atrelados às mudanças que ocorrem na sociedade. Partindo desse pressuposto é de extrema importância que as políticas públicas sejam pensadas com essa ótica pedagógica, uma vez que nossos estudantes também aprendem por meio de outros meios na comunidade.

A escola, para o século XXI deve estar aberta ao diálogo, ouvindo os anseios e desejos dos jovens no que se refere à aprendizagem significativa. Portanto, deve-se pensar em como relacionar o currículo dado com a realidade local dos estudantes. Valorizando os conhecimentos socioculturais, socioemocionais, socioeconômicos e socioambientais que os estudantes possuem. Partindo dessa análise, buscar e reflexões e possibilidades para o processo ensino e aprendizagem de forma, que essa aprendizagem se torne significativa para o estudante.

Analisando a clientela da Escola Estadual de Ensino Fundamental e Médio “José Teixeira Fialho", a equipe escolar decidiu que seria importante trabalhar projetos de ensino com enfoque no currículo, mas vinculados às vivencias dos educandos. A partir de então, os professores e demais profissionais da escola se reuniram formando equipes de trabalho por temas geradores.

\section{Contextualização da situação-problema}

O que motivou a construção da presente pesquisa é a forma que geralmente a educação ambiental e trabalhada nas escolas. Sendo a mesma teórica e descontextualizada da realidade local. Muitas vezes são trabalhados os problemas encontrados em outras regiões, outros continentes e esquecemos que ações realizadas no nosso cotidiano têm gerado os impactos a níveis globais, como o aquecimento global, efeito estufa, erosões no solo, mudanças climáticas, escassez de água, dentre outros.

Em função de tudo isso, a Educação Ambiental tem o importante papel de fomentar a percepção da necessidade de interação com o meio ambiente, buscando uma relação harmoniosa, consciente do equilíbrio dinâmico na natureza, possibilitando, por meio de novos conhecimentos, valores e atitudes a inserção do educando e do educador no processo de transformação do quadro ambiental em que se encontra o planeta.

Lima (1984, citado por GUIMARÃES, 1995), onde diz:

(...) a educação ambiental exige uma postura crítica e um corpo de conhecimento produzido a partir de uma reflexão sobre a realidade vivenciada. Sendo uma proposta essencialmente comunitária, materializa-se através de uma prática cujo objetivo maior é a promoção de um comportamento adequado à proteção ambiental. Comporta uma concepção desalienante, porquanto pressupõe ações voltadas para o surgimento de novos valores, onde a participação é um princípio fundamental.

Além da parte teórica não podemos esquecer que educação ambiental sem prática não existe. Porque todos já sabem dos problemas existentes no meio ambiente. Por isso temos que aplicar educação ambiental teórica e prática, para que possamos ver o surgimento de um mundo ético, de qualidade, com práticas cidadãs ativas, indispensáveis à democracia e à emancipação do indivíduo, protegendo a biodiversidade de nosso planeta.

Guimarães (1995), também nos fala: 
Qual a separação que existe entre o ser humano e o meio ambiente, se a todo o momento o ser humano aspira para o seu interior o ar que circunda ingere a água que bebe, o alimento que come, exterioriza e interioriza sentimentos para com outra pessoa, uma flor, um animal, uma paisagem? Uma relação intrínseca e vital com o ambiente.

Confirma-se assim na Educação Ambiental um conhecido lema ecológico, o agir localmente, pensando globalmente. Sabendo que pensar e agir deverão estar interligados para que as ações planejadas sejam executadas.

A pesquisa foi realizada no Distrito de Imburana, um dos sete Distritos da cidade de Ecoporanga-ES, criado pela Lei Estadual no 3.046, de 14 de maio de 1976. Fica aproximadamente a 208 metros de altitude, a uma distância de $19 \mathrm{~km}$ da sede. O distrito tem uma população de aproximadamente de 1.200 habitantes. Segundo relatos de moradores antigos da região, a origem do nome é devido à grande quantidade da árvore Imburana (Commiphora leptophloeos), que ocorria na localidade, uma espécie da flora Brasileira, característica da vegetação de Caatinga, que apresenta portes variáveis conforme o ambiente onde se desenvolve.

O Distrito é composto de grandes fazendas, pequenas propriedades rurais e assentamentos. É cortado pelo Córrego do Facão. Um córrego que se encontra assoreado devido à ação antrópica. Encontramos esgotos e muito lixo dentro do Rio. Ao redor do Distrito temos lavouras e pastagens. Também encontramos áreas que já se tornaram inservíveis para o cultivo devido a erosões, tornando as terras sem matéria orgânica e improdutivas.

A escola é composta por uma clientela oriunda dos Distritos: Imburana, Cotaxé e Muritiba. Também se encontra estudantes que vem de assentamentos e acampamentos do entorno. Atualmente está com 250 estudantes. Dentre estes tem 38 estudantes provenientes da Educação Especial. Os estudantes têm ligação direta com as atividades do campo como: agricultores, pequenos produtores rurais, vaqueiros, extração do granito.

Sabendo da atual situação que encontra o meio ambiente, percebe-se a importância de trabalhar este conceito Acerca da Educação Ambiental, Lima (1984, citado por GUIMARÃES, 1995). Onde diz:

$\mathrm{Na}$ Carta de Belgrado estão explicitados as metas e os objetivos da Educação Ambiental, onde o princípio básico é a atenção com o meio natural e artificial, considerando os fatores ecológicos, políticos, sociais, culturais e estéticos. Determina também que a educação deve ser contínua, multidisciplinar, integrada dentro das diferenças regionais, voltada para os interesses nacionais centrada no questionamento sobre o tipo de desenvolvimento. Tem como meta prioritária a formação nos indivíduos de uma consciência coletiva, capaz de discernir a importância ambiental na preservação da espécie humana e, sobretudo estimular um comportamento cooperativo nos diferentes níveis das relações inter e intranacionais.

(...) a educação ambiental assume a posição de promover conhecimento dos problemas ligados ao ambiente, vinculando - os a uma visão global; preconiza, também, a ação permanente, através da qual a comunidade toma consciência de sua realidade global, do tipo de relações que os homens mantêm entre si e com a natureza, dos problemas derivados destas relações e de suas causas profundas.

Seguindo este mesmo raciocínio Gonsalves (1984, citado por GUIMARÃES, 1995), onde nos orienta:

Provavelmente através do processo educativo, feito de Forma ativa, e da escola aberta e participativa, as atividades desenvolvidas em relação ao meio ambiente permitirão a abstração de valores muito mais duradouros do que os que têm conseguido a escola dita 
tradicional.

De acordo com Guimarães (1995):

Em EA é preciso que o educador trabalhe intensamente a integração entre ser humano e ambiente e se conscientize de que o ser humano é natureza e não apenas parte dela. Ao assimilar esta visão (holística), a noção de dominação do ser humano sobre o meio ambiente perde seu valor, já que estando integrado em uma unidade (ser humano/natureza) inexiste a dominação de alguma coisa sobre a outra, pois já não há mais separação. Podendo assim resultar em atitudes harmoniosas por parte do ser humano, em consonância com as relações naturalmente existentes entre os elementos vivos e elementos não-vivos de um ecossistema dinamicamente equilibrado.

As atividades econômicas realizadas na região como a extração do granito, agricultura e pecuária extensiva para criação de gado leiteiro e de corte tem levado ao desmatamento quase total das matas que existiam no entorno do Distrito. Hoje o que se encontra é pequenos fragmentos da Mata Atlântica em locais de difíceis acessos e que o homem ainda não teve como retirá-la.

Outro problema enfrentado é a ação humana que muitas vezes não leva em consideração que atitudes simples, ações cidadãs tornam o ambiente limpo e agradável. Encontra-se muito lixo doméstico e esgotos sendo despejados diretamente no Córrego que passa dentro do Distrito. As nascentes estão sem cobertura vegetal o que leva a ser considerado o que se encontra em estado mais crítico em relação às secas.

O Distrito vem enfrentando fortes secas nos últimos anos, sendo que em 2015 e 2016 os moradores foram abastecidos por caminhão pipa, pois não havia vazão para a captação de água do Rio.

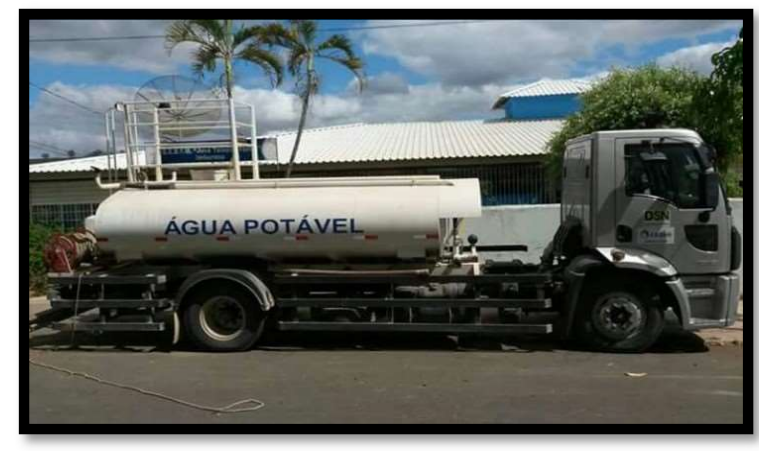

Figura 1: Caminhão pipa em frente à escola para abastecimento com água potável.

Outro problema sério no Distrito é o uso de agroquímicos pela comunidade na pecuária e nas lavouras.

As terras carregadas pelas águas das chuvas levam para os rios, lagoas e barragens os resíduos de agrotóxicos, comprometendo a fauna e a flora aquática, além de comprometer as águas captadas com a finalidade de abastecimento. Podem também provocar o aumento das pragas ao invés de combatê-las, pois na medida em que se usam insumos químicos as pragas tornam-se mais resistentes, necessitando de agrotóxico cada vez mais forte, desse modo, agredindo ainda mais o ambiente e dizimando até os próprios predadores naturais das pragas.

A equipe escolar sabe que "o conhecimento não é dado nem adquirido, ele é mostrado, acentuado, demonstrado pelo professor e, a partir dessas operações, ele é construído pela criança" (FRIEDRICH, 2012). Não só pela Criança, mas, também pelo adolescente, pelos jovens e adultos. Pois todos, alunos, professores e comunidade aprendem muito com ações práticas no cotidiano escolar. A interação com o meio é uma ferramenta muito rica para produção de conhecimentos. 
Segundo Guimarães (1995), diz que:

Os seres humanos superam, e muito, os seus limites biológicos de intervenção no meio, atingindo duramente a capacidade suporte do ambiente. Isso deu-se principalmente a partir da Revolução Industrial, em que o ser humano conquista tecnologia cada vez mais poderosa. Tecnologia que traz intrinsecamente em sua concepção valores antropocêntricos, consumistas, fragmentados e por consequência destrutivos ambientalmente, em que a qualidade e a quantidade da intervenção dos seres humanos sobre a natureza por meio dessa tecnologia assumiram parâmetros atuais, com grandes e nefastos impactos ambientais.

A sustentabilidade deve ser a mola propulsora sempre que se expressa gestão e educação ambiental.

Não podemos retirar da natureza mais do que ela pode nos oferecer. Além disso, é necessário de uma ação consciente em relação ao uso dos recursos naturais para a preservação e a perpetuação de um ambiente harmonioso para as futuras gerações. È necessário um pensar coletivo, sobre fatores bióticos e abióticos para que entendamos dessa relação de interdependência, onde precisa existir um respeito para com o ambiente e tudo que nele existe.

No Currículo do Estado do Espírito Santo, SEDU, 2009, na p.41 e 42, no item 3.4 encontra-se a importância da Educação Ambiental. Veja a seguir o que nos apresenta este item:

A Educação Ambiental é um tema transversal a ser trabalhado em todos os níveis e modalidades de ensino na educação básica. Constitui - se em um processo permanente, fundamentado no respeito a todas as formas de vida, no reconhecimento da complexidade socioambiental e em valores e ações que contribuam para a (trans) formação ao invés de produzirmos alimentos, habitações e bens muito duráveis, são produzidos bombas e bens com duração muito reduzida. Os serviços deveriam ser realizados por equipamentos coletivos. Deveria ser estabelecida uma nova ética que rejeitasse a exploração, o consumismo e a exaltação da produção como fim por si só. Será necessária uma nova forma de agricultura e de indústria, uma nova urbanização, e um novo urbanismo e uma nova forma de produção e consumo com largos benefícios que terão de lidar com a complexidade da realidade. A educação para o ambiente deve formular constantemente seus métodos, conteúdos. Constitui - se em um processo permanente, fundamentado no respeito da complexidade socioambiental e em valores e ações que contribuam para a (trans) formação do ser humano. Seu ideário é as formações de sociedades que são, ao mesmo tempo, ecologicamente prudentes, economicamente viáveis, socialmente justas, culturalmente diversas e politicamente atuantes. A promoção da Educação Ambiental em todos os níveis e modalidades de ensino está estabelecida na Lei 9795/99 e contribuirá para a formação humana, se colocada nos princípios da solidariedade, da cooperação, da democracia, da justiça social e ambiental, se promover a emancipação dos sujeitos para uma participação social efetiva, com respeito à alteridade e à diversidade social, ética e cultural dos povos. $O$ adjetivo ambiental na educação nos dá a ilusão de que se a Educação Ambiental for desenvolvida nas escolas, valores e atitudes em relação ao meio ambiente serão transformados qualitativamente. Ainda que a Educação Ambiental esteja ratificada no currículo por meio do aparato legal, é preciso situá - La historicamente e explicitar as contradições e as causas do antagonismo cultivado entre ser humano e natureza. A educação ambiental ainda vem acontecendo nas escolas de forma episódica, eventual e de modo paralelo ao desenvolvimento curricular. Para que a Educação Ambiental torne - se efetiva nas escolas é necessária uma mudança de valores e postura de toda a comunidade, no envolvimento com os problemas e as questões socioambientais em termos locais e globais. Além de incluir a temática no projeto político pedagógico da escola, é preciso que a Educação Ambiental seja vista como parte de um plano coletivo da comunidade escolar. A educação ambiental pressupõe a implementação de metodologias participativas, cooperativas, interdisciplinares, que se definem no compromisso de qualificar a relação com o meio ambiente, considerando a complexidade e a multidimensionalidade da questão ambiental no exercício da participação social e a defesa da cidadania como práticas indispensáveis à democracia e à emancipação socioambiental. (BRASIL, 1996)

As Diretrizes Curriculares Nacionais da Educação Básica (BRASIL, 1996) afirmam que: 
Uma escola que inclui todos supõe tratar o conhecimento como processo e, portanto, como uma vivência que não se harmoniza com a ideia de interrupção, mas sim de construção, em que o estudante, enquanto sujeito da ação, está continuamente sendo formado, ou melhor, formando-se, construindo significados, a partir das relações dos homens entre si e destes com a natureza.

A escola quando trabalha a educação ambiental não pode ficar trancada dentro de seus muros. Mas permitir uma participação multiprofissional. E buscar parcerias interdisciplinares, transdisciplinares, já que esse é um tema que transpassa qualquer disciplina e que se encaixa em cada ação praticada por cada ser humano frente às causas e consequências vivenciadas e criadas pelas ações antrópicas. Com essa visão abrangente, pode-se dizer que o trabalho poderá ter os objetivos alcançados.

O trabalho de conscientização deve ser mantido como uma teia, formada por vários fios. Cada fio dando sua contribuição sem querer ser maior ou melhor que o outro, mas defendendo sua posição e seu espaço. Assim deve ser cada membro que compõe uma sociedade cidadã. Cada ser vivo fazendo sua parte, para que todos sejam beneficiados.

Percebe-se muito apoio das equipes gestoras o apoio a eventos culturais e pouco incentivos às práticas experimentais. Geralmente as equipes pedagógicas valorizam muito ações que envolvam a cultura, mas urge a necessidade de equilíbrio entre os campos para a formação plena do cidadão na perspectiva de uma educação integral: Campo sociocultural, socioemocional, socioeconômico e socioambiental.

Devem-se valorizar as produções artísticas e as produções realizadas pelos estudantes; o ser humano para uma aprendizagem plena precisa contar com um ambiente que colabore para sua segurança e ao protagonismo, deve-se levar o estudante a pensar sobre a produção de bens e consumo e como podemos equilibrar essas ações, e precisa-se de uma nova visão sobre a postura adotada quanto ao meio ambiente. Tem que relacionar a Ciência a Tecnologia e a sociedade para produção de forma consciente.

Segundo Guimarães (1995):

Conforme os princípios básicos descritos pela Educação Ambiental, o planejamento das ações deve ser essencialmente participativo: professores, alunos segmentos comunitários, agentes sociais de uma prática social em que cada contribua com sua experiência acumulada, sua visão de mundo e suas expectativas, aflorando condições. Dessa forma, facilita a compreensão e a atuação integral e integrada sobre a realidade vivenciada. As pessoas envolvidas nesse processo terão, como um exercício de cidadania, uma participação ativa na elaboração teórica e prática das ações para a superação dos problemas diagnosticados. Simultaneamente, essas ações estarão comprometidas com a realidade ambiental do local em que se vivencie esse processo.

O cotidiano escolar é muito rico para se trabalhar a educação ambiental. É ali, onde estudantes passam boa parte de seu dia convivendo com pessoas diferentes e com pensamentos diferentes e que se unem em busca de um só objetivo: A aprendizagem. E diante disso, pode-se utilizar desse meio para o entendimento da Educação Ambiental. Cunha (1999) define os princípios básicos do pragmatismo como,

[...] o pensamento e a ação devem formar um todo indivisível, o que implica tratar qualquer formulação teórica como hipótese ativa que carece de demonstração em situação prática de vida; as constantes transformações sociais fazem com que a realidade não constitua um sistema acabado e imutável; a inteligência garante ao homem a capacidade de alterar as condições de sua própria experiência. Para os pragmatistas, o terreno em que se dá a transmissão do conhecimento, particularmente a escola, pode tornar-se um campo fértil de experimentação de teses filosóficas. 
Na escola, hipóteses são testadas, confirmadas ou refutadas. Nesse contexto, em 2015, estudantes ainda sentavam sobre as mesas do refeitório; iam ao sanitário e deixavam torneiras abertas, os bebedouros estavam velhos e as torneiras desperdiçando água, as mesas eram rabiscadas e sujas. Os estudantes e professores encontravam-se muito desmotivados frente aos resultados obtidos em avaliações externas em anos anteriores. Foi feito nessa Instituição um trabalho de resgate de valores e respeito coletivo.

Para Hernández et al. (1998),

A função do projeto é favorecer a criação de estratégias de organização dos conhecimentos escolares em relação a: 1) o tratamento da informação; e 2) a relação entre os diferentes conteúdos em torno de problemas ou hipóteses que facilitem aos alunos a construção de seus conhecimentos, a transformação da informação procedente dos diferentes saberes disciplinares tem conhecimento próprio.

Para Hernández et al. (1998), o trabalho com projetos,

Aproxima-se da identidade dos alunos e favorecer a construção da subjetividade, longe de um prisma paternalista, gerencial ou psicologista, o que implica considerar que a função da escola não e apenas ensinar conteúdos, nem vincular a instrução com a aprendizagem. Revisar a organização do currículo por disciplinas e a maneira de situá-lo no tempo e nos espaços escolares. O que torna necessária a proposta de um currículo que não seja uma representação do conhecimento fragmentada, distanciada dos problemas que os alunos vivem e necessitam responder em suas vidas, mas, sim, solução de continuidade. Levar em conta o que acontece fora da escola, nas transformações sociais e nos saberes, a enorme produção de informação que caracteriza a sociedade atual, e aprender a dialogar de uma maneira crítica com todos esses fenômenos.

Para Hernández et al. (1998) a pesquisa apresenta um papel de suma importância no ensino porque,

A finalidade do ensino é promover, nos alunos, a compreensão dos problemas que investigam. Compreender é ser capaz de ir além da informação dada, é poder reconhecer as diferentes versões de um fato e buscar explicá-las além de propor hipótese sobre as consequências dessa pluralidade de pontos de vista.

Deve-se buscar uma prática pedagógica onde o ser humano seja mais livre para expor suas ideias, e reflexivamente descobrir-se e conquistar-se como sujeito de sua própria destinação histórica. A Educação Libertadora, enquanto processo de formador de agentes de transformação da ética da população quanto ao desenvolvimento de novas atitudes, ao trato com o meio ambiente, constituindo de fato a Educação Ambiental.

\section{Apresentação da proposta para solucionar o problema identificado}

De acordo com os estudos realizados por área de conhecimento, baseando-se nas explanações de Antoni Zabala, a escola vem trabalhando com sequências didáticas, metodologias ativas, por meio de projetos de ensino e projetos científicos que valorizam a diversidade encontrada no contexto escolar, construindo planos de aula com uma abordagem dos conteúdos conceituais, procedimentais e atitudinais. A aprendizagem dos conteúdos de acordo com suas tipologias vem gerando bons resultados. Diante do exposto acima, podemos dizer que: Não basta fazer, é preciso saber fazer. E na educação procura-se essa constante transformação.

Segundo Gardner (1995): “Os seres humanos são considerados, por excelência, as criaturas da comunicação, que armazenam significados através de palavras, desenhos, gestos, números, padrões musicais 
e um grande número de outras formas simbólicas".

Na EEEFM “José Teixeira Fialho", procura-se trabalhar teoria e prática de forma muito intrínseca. E com isso conseguiu-se um saldo muito positivo através das ações e projetos voltados para Ciência, tecnologia, sociedade e ambiente (CTSA). No quadro 1, estão os projetos que foram/serão desenvolvidos e o que se espera.

Quadro 1: Projetos que foram/serão desenvolvidos.

\begin{tabular}{|c|c|c|c|}
\hline Ações & Série & Período & Resultado esperado \\
\hline $\begin{array}{l}\text { Construir sequências didáticas abordando } \\
\text { diversos conceitos sobre a Educação } \\
\text { Ambiental, e sustentabilidade. }\end{array}$ & $\begin{array}{l}\text { 60 Ano do EF a } \\
\text { 3ạ Série do } \\
\text { Ensino Médio }\end{array}$ & Fevereiro & $\begin{array}{l}\text { Com essa ação, espera-se que os estudantes } \\
\text { tenham os conhecimentos básicos sobre os } \\
\text { principais conceitos utilizados dentro do } \\
\text { contexto da Educação Ambiental. }\end{array}$ \\
\hline $\begin{array}{l}\text { Construir panelas a partir de coletas de } \\
\text { alumínios, tais como: latas de cervejas, } \\
\text { refrigerantes, sucos, e outros utensílios de } \\
\text { alumínio que não estão em uso. }\end{array}$ & 9o Ano do EF & $\begin{array}{l}\text { Março a } \\
\text { Dezembro }\end{array}$ & $\begin{array}{l}\text { Reciclar alumínio e entregar ao setor que } \\
\text { fabrica panelas na comunidade. O objetivo } \\
\text { dessa ação é diminuir a quantidade de } \\
\text { alumínio que encontramos descartados } \\
\text { incorretamente. }\end{array}$ \\
\hline $\begin{array}{l}\text { Produzir defensivo biológico, evitando a } \\
\text { utilização dos agroquímicos. }\end{array}$ & 1a série do EM & $\begin{array}{ll}\text { Março a } \\
\text { outubro. }\end{array}$ & $\begin{array}{l}\text { Produzir extratos naturais obtendo defensivos } \\
\text { biológicos, menos nocivos ao ambiente, sendo } \\
\text { utilizados pela comunidade do Distrito. }\end{array}$ \\
\hline $\begin{array}{l}\text { Reflorestar a Nascente do Córrego do facão } \\
\text { com mudas nativas doadas pela Secretaria de } \\
\text { Meio ambiente. Essa ação será realizada com } \\
\text { a ajuda dos proprietários do terreno onde se } \\
\text { encontra a nascente. A comunidade irá dar o } \\
\text { suporte. }\end{array}$ & $\begin{array}{l}\text { 60 ano do EF a 3a } \\
\text { série do EM }\end{array}$ & $\begin{array}{l}\text { Abril a } \\
\text { novembro }\end{array}$ & $\begin{array}{l}\text { Adquirir as mudas de plantas nativas e realizar } \\
\text { o plantio por meio de colabores, sendo eles: os } \\
\text { donos do terreno, comunidade escolar, e } \\
\text { comunidade do Distrito. }\end{array}$ \\
\hline $\begin{array}{l}\text { Participar dos eventos locais sobre a } \\
\text { temática. }\end{array}$ & $\begin{array}{l}\text { Professores e } \\
\text { demais } \\
\text { funcionários da } \\
\text { escola. }\end{array}$ & $\begin{array}{l}\text { Fevereiro a } \\
\text { Dezembro }\end{array}$ & $\begin{array}{l}\text { A gestão irá incentivar a participação dos } \\
\text { profissionais nos seminários, fóruns e demais } \\
\text { eventos que foquem a temática gestão e } \\
\text { Educação Ambiental. }\end{array}$ \\
\hline $\begin{array}{l}\text { Realizar a Coleta seletiva e reciclagem como } \\
\text { instrumentos de aprendizagem nas } \\
\text { disciplinas da área de ciências da natureza e } \\
\text { matemática com enfoque sustentável }\end{array}$ & $\begin{array}{l}\text { 60 ano do EF a 3a } \\
\text { Série do EM }\end{array}$ & $\begin{array}{l}\text { Fevereiro a } \\
\text { Dezembro }\end{array}$ & $\begin{array}{l}\text { Promover por meio de gincana o recolhimento } \\
\text { de objetos que podem ser reciclados. Ao final } \\
\text { a turma que mais recolher ganha um passeio } \\
\text { ecológico. O objetivo é recolher junto com os } \\
\text { familiares lixos secos que estão no entorno das } \\
\text { casas e adjacências. }\end{array}$ \\
\hline $\begin{array}{l}\text { Realizar o Levantamento etnobotânico e } \\
\text { Preservação do uso de Plantas Medicinais do } \\
\text { município de Ecoporanga-ES, principalmente, } \\
\text { as plantas utilizadas na Comunidade do } \\
\text { entorno escolar. }\end{array}$ & $\begin{array}{l}\text { 60 ao 9응 Ano do } \\
\text { EF. }\end{array}$ & $\begin{array}{l}\text { Março a } \\
\text { Dezembro }\end{array}$ & $\begin{array}{l}\text { Realizar o levantamento das principais plantas } \\
\text { que são utilizadas como medicinais e ensinar o } \\
\text { manejo das mesmas em hortas no próprio } \\
\text { quintal. }\end{array}$ \\
\hline
\end{tabular}

\section{Análise dos resultados obtidos/previstos}

Através dos projetos de ensino e pesquisa, bem como o uso de metodologias ativas, realizados com os estudantes da Escola José Teixeira Fialho, foi possível analisar de forma positiva a importância de um trabalho contextualizado, que leve em consideração as vivências do estudante, respeitando cada indivíduo.

Os projetos trouxeram muitas reflexões e mudanças de postura nos estudantes, bem como o senso de pertencimento a escola e ao Distrito onde vivem; procurando incentivar os pais a cuidarem dos recursos naturais, bem como as mudanças na forma como enxergavam o meio ambiente.

A escola tem melhorado em todos os aspectos. Em relação aos espaços físicos, temos uma quadra recém-inaugurada e que serve para diversos eventos da escola. Os estudantes e comunidade local criaram o hábito de zelo e cuidado pelo patrimônio público. Em relação às salas de aula, todas foram climatizadas, por 
meio do Programa Ensino Médio Inovador com a aquisição de aparelhos de ar condicionados. Os professores estão buscando continuamente formação continuada. A escola vem participando de eventos externos, apresentando os projetos, sendo classificados em quase todos devido às práticas exitosas que são realizadas na Instituição por meio dos projetos de Ensino e pesquisa. Todas essas mudanças de paradigmas na educação têm impactado de forma positiva nos resultados qualitativos e quantitativos da escola.

Para os próximos anos, a equipe escolar vem se apropriando das tecnologias digitais e comunicação na educação, realizando inscrições nas Olimpíadas de foguetes, Olimpíada Brasileira de Astronomia, Olimpíada Brasileira de Matemática, Olimpíada Brasileira de Ciências, projetos científicos com pesquisa de campo, utilização de máquinas e equipamentos que melhorem o processo ensino - aprendizagem, climatização dos ambientes escolares e essas ações e Práticas Pedagógicas Inovadoras vem gerando bons resultados na evolução do processo educacional da Instituição.

Na tabela 1, será demonstrado o rendimento quantitativo da escola, indicando os avanços obtidos a partir do momento que a escola passou a adotar metodologias ativas, por meio de projetos de ensino.

Tabela 1: Indicadores de produtividade Institucional.

\begin{tabular}{|l|l|l|l|l|l|l|}
\hline & Matrículas & Aprovação & Reprovação & Evasão & Transferência & Aproveitamento Total \% \\
\hline 2014 & 255 & 201 & 54 & 18 & 24 & $78,8 \%$ \\
\hline 2015 & 235 & 202 & 33 & 15 & 24 & $85,9 \%$ \\
\hline 2016 & 212 & 187 & 25 & 3 & 46 & $88,2 \%$ \\
\hline 2017 & 206 & 203 & 3 & 0 & 21 & $98,5 \%$ \\
\hline 2018 & 197 & 188 & 09 & 2 & 49 & $95,43 \%$ \\
\hline
\end{tabular}

Diante dos relatos supracitados e os índices que serão apresentados nos quadros totalizadores de cada ano, percebe-se o quanto a escola está evoluindo. Sabemos que nossos estudantes precisam de oportunidades. E essas oportunidades são produzidas por meio de uma educação de qualidade, que segue as atuais mudanças e que respeita as vivências da comunidade escolar. $O$ trabalho realizado na Instituição tem resgatado estudantes que estavam desmotivados. A escola quase não existe mais estudantes que se evadem durante o ano, a comunidade do distrito abraçou a escola e acredita no trabalho que é desenvolvido na Instituição. Com isso entende-se a importância da palavra corresponsabilização.

\section{REFERÊNCIAS}

BRASIL. Ministério da Educação e do Desporto. Secretaria de Educação Fundamental. Lei n. 9.394, de 20 de dezembro de 1996. Estabelece as diretrizes e bases da educação nacional. Brasília: MEC, 1996.

CUNHA, M. V.. John Dewey: uma filosofia para educadores em sala de aula. 3 ed. Petrópolis: Vozes, 1999.

FRIEDRICH, J. L. V.. Mediação, aprendizagem e desenvolvimento: uma leitura filosófica e epistemológica. São Paulo: Mercado de Letras, 2012.
GARDNER, H.. Inteligências Múltiplas: A teoria na prática. Porto Alegre: Artes Médicas, 1995.

GUIMARÃES, M.. A dimensão ambiental na educação. 2 ed. Campinas: Papirus, 1995.

HERNÁNDEZ, F.; VENTURA, M.. A organização do currículo por projetos de trabalho: o conhecimento é um caleidoscópio. Porto Alegre: ArtMed, 1998.

A CBPC - Companhia Brasileira de Produção Científica (CNPJ: 11.221.422/0001-03) detém os direitos materiais desta publicação. Os direitos referem-se à publicação do trabalho em qualquer parte do mundo, incluindo os direitos às renovações, expansões e disseminações da contribuição, bem como outros direitos subsidiários. Todos os trabalhos publicados eletronicamente poderão posteriormente ser publicados em coletâneas impressas sob coordenação da Sapientiae Publishing, da Companhia Brasileira de Produção Científica e seus parceiros autorizados. Os (as) autores (as) preservam os direitos autorais, mas não têm permissão para a publicação da contribuição em outro meio, impresso ou digital, em português ou em tradução. 